Article

\title{
A Study on Energy-related GHG Mitigation Scenario in Thailand
}

\author{
Weerin Wangjiraniran ${ }^{*}$ and Bundhit Eua-arporn \\ Energy Research Institute, Chulalongkorn University, Phayathai, Phatumwan, Bangkok 10330, Thailand \\ E-mail: weerin@eri.chula.ac.th*
}

\begin{abstract}
The objective of this study is to evaluate the potential of greenhouse gases mitigation for major policy options in Thailand. Three scenarios with different prospects on energy-related greenhouse gases are explored. The picture with no change of government policy which is relied on the existing plan namely 'reference scenario' is simulated as a baseline scenario. A case with undergo progress of the committed plan namely 'case without plan' is compared to an alternative case with more concern on greenhouse gases reduction called 'case with additional plan'. Thus, the impact of existing and non-existing measures can be evaluated comparatively. The results show the quantitative assessment of greenhouse gases mitigation potential for the selected measures. Fuel economy improvement, bio-fuel option as well as nuclear power are prioritized as high potential for greenhouse gases mitigation, while the options of transportation mode switching and energy efficiency in industry have less impact. The results also show the gap between current target and the applicable potential, particularly the term of energy efficiency.
\end{abstract}

Keywords: Greenhouse gas mitigation, energy outlook, energy policy, energy efficiency.

ENGINEERING JOURNAL Volume 16 Issue 2

Received 23 November 2011

Accepted 4 February 2012

Published 1 April 2012

Online at http://www.engj.org

DOI:10.4186/ej.2012.16.2.19 


\section{Introduction}

Emerging countries, e.g. China, India and Asian countries will be set to play increasingly an important role in global energy market within a decade ahead. Many challenges on energy-related GHG mitigation are necessary to overcome, in particular the balance of energy security and global warming awareness under the circumstance of rapid economic growth and high rate of energy consumption in this region. To tackle these issues, it is necessary to draw the basic information on the outlook of energy-related GHG in the potential countries in this region to create the concrete active action plan for GHG mitigation.

A study on energy and GHG system in Thailand has been progressively developed by various approaches and dimensions. Santisirisomboon et al. [1] applied the least cost method to evaluate the power generation plan and allowed the target of $\mathrm{CO} 2$ emission mitigation to be the constraint of the calculation. Tanatvanit et al. [2] applied a simulation model to develop the energy demand and supply system and focused on the impact of renewable energy deployment. Wangjiraniran et al. [3] developed a baseline scenario for Thailand energy system by using simulation model. Load forecast and outlook for power generation has been evaluated. Wangiiraniran et al. [4] evaluated the impact of fuel options, e.g. coal, natural gas and nuclear, on the overall generation cost, GHG emission and resource depletion for power generation.

The objective of this study is to explore the scenarios of energy-related greenhouse gas mitigation in Thailand to 2030. The picture with no change of government policy which is relied on the existing plan namely 'reference scenario' is simulated. Ambitious target of renewable energy deployment with the priority of energy supply security is adopted. Alternatively, a case with undergo progress of the committed plan namely 'case without plan' is also compared to reveal the impact of government policy uncertainty, particularly nuclear power and implementation of road-to-rail policy. This scenario will also present the pessimistic prospect on renewable energy development. On the other hand, a case with more concern on greenhouse gas emission reduction called 'additional plan' is comparatively simulated to evaluate the impact of additional non-existing policies on greenhouse gas mitigation. In this case, the proposed measures in the energy efficiency scheme with more nuclear power generation are considered to minimize the energyrelated greenhouse gas in Thailand.

\section{Methodology}

In this study, a scenario-based energy accounting model, i.e. LEAP (Long-Range Energy Alternative Planning system) [5] has been applied for creating long-term future scenarios. It is particularly designed for balancing energy system with an integrated environmental database.

Figure 1 illustrated the structure of the utilized simulation model. In the demand module, final energy demand is derived by the products of key drivers and energy intensities by sectors. In the transformation module, the requirement of final energy is initially fulfilled with the production of existing capacities. Primary resource is withdrawal by the required feedstock during the transformation process. The entire energy system is balance by exporting the surplus and importing the shortage energy. Under this scheme, energy-related GHG will be evaluated endogenously based on the energy consumption at final energy and transformation module with the emission factor of IPCC tier 1, integrated in the Technology Database (TED) module.

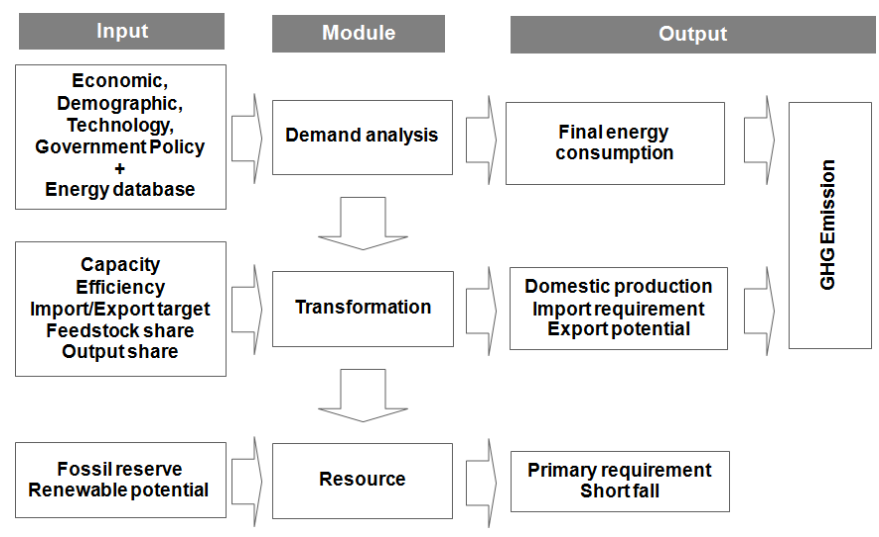

Fig. 1. Calculation structure. 
In order to reveal the contribution of energy-related GHG, the analysis is disaggregated into a hierarchical structure, comprising of the 7 major energy-related sectors in harmony with the national energy database [6]. The structure of calculation is illustrated in Fig. 2. The activities of transportation and industrial sectors are disaggregated by 5 transportation modes and 9 industrial sub-sectors classification, respectively. The activities of power generation are classified by individual process to distinguish the variation of emitted greenhouse gas. In this case, only domestic power production is accounted for the source of greenhouse gases in the power sector. The remainders of other sectors are considered as a whole sector aggregation. This structure relies definitely on the national energy database classified by the Thailand Standard Industrial Classification (TSIC).

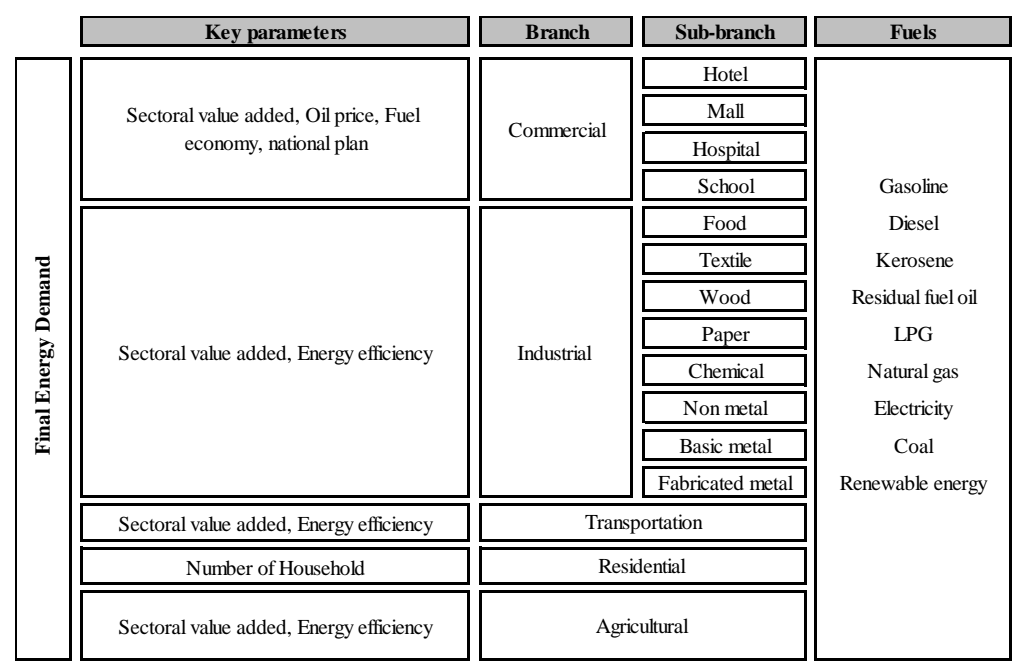

(a) Final energy demand

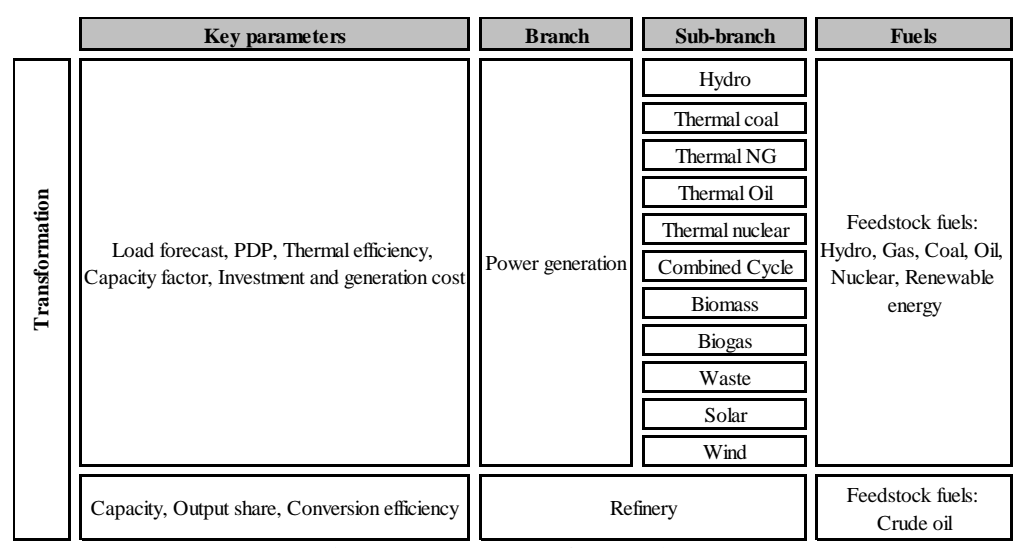

(b) Energy transformation

Fig. 2. Structure of disaggregated energy database.

Final energy consumption is simply evaluated by the product of driving activities and sectoral energy intensity as illustrated in the following equation

$$
\text { Energy demand }[\mathrm{ktoe}]=\text { Driver }[\mathrm{unit}] \mathrm{x} \text { Energy intensity [ktoe/unit] }
$$

For industrial, commercial and agricultural sectors, it has been proved that energy consumption depends strongly on the growth of economic condition [7]. Hence it is presumably evaluated by the product of sectoral/sub-sectoral value-added and energy intensity in each branch. In the residential sector, numbers of households are considerably the major driver for the fuel consumption [2]. Substitution of traditional fuel with modern energy is assumed to represent pattern of energy use in the future. For the transportation sector, it is known that energy demand is basically evaluated from the travelling demand and number of vehicle ownership. These parameters are normally estimated as a function of income, 
population, local user behavior and so on [7]. However, the database for transportation activities in Thailand is insufficient to analyze by this approach. In this study, it is assumed that energy demand in road transport are driven mainly by the macro-economic growth and partly influenced by the energy-price movement. Sensitivity of the oil price to the oil demand can be expressed in term of the oil intensity illustrated in Fig. 3. Historical data shows that the rising of oil price caused the lower oil intensity in Thailand for the last decade. Double oil price affects to the reduction of oil intensity by approximately 15 percent. Energy consumption due to fuel switching process is evaluated based on fuel economy for each fuel type as illustrated in Table 1. In railway mode of transport, energy consumption is definitely based on the national plan of mass transit expansion in Bangkok and intercity high speed railway. It is assumed that road transport consume more energy than massive railway at the factor of 4.25 [8]. In the mean time, air transport is assumed to take more energy than high speed train at the factor of 6.25 [8]. Fuel consumptions in water and air transport can be evaluated by the product of the economic activity growth and energy intensity.

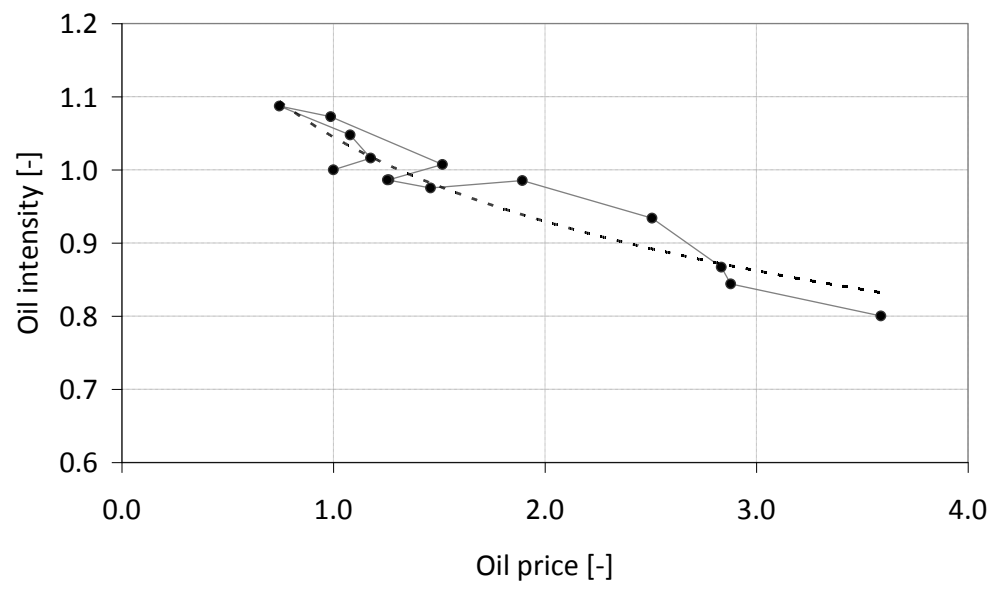

Fig. 3. Correlation of oil intensity and crude oil price (Index $1995=1$ ).

Table 1. Fuel economy and conversion factor for fuel switching in road transport.

\begin{tabular}{|c|c|c|c|c|c|c|c|c|}
\hline \multirow{3}{*}{ Parameters } & \multirow{3}{*}{ Units } & \multicolumn{4}{|c|}{ Gasoline engine } & \multicolumn{3}{|c|}{ Diesel engine } \\
\hline & & NGV & LPG & E10 & Gasoline & NGV & B5 & Diesel \\
\hline & & kg & liter & liter & liter & $\mathrm{kg}$ & liter & liter \\
\hline $\begin{array}{l}\text { Fuel } \\
\text { economy }\end{array}$ & $\mathrm{km} /$ unit & 15.26 & 11.1 & 13.08 & 13.47 & 2.21 & 2.5 & 2.5 \\
\hline $\begin{array}{l}\text { Heating } \\
\text { value }\end{array}$ & MJ/unit & 42.19 & 26.62 & 30.74 & 31.48 & 42.19 & 36.37 & 36.42 \\
\hline $\begin{array}{l}\text { Travelling } \\
\text { per unit } \\
\text { energy } \\
\text { consumption }\end{array}$ & $\mathrm{km} / \mathrm{MJ}$ & 0.36 & 0.42 & 0.426 & 0.428 & 0.05 & 0.07 & 0.07 \\
\hline $\begin{array}{l}\text { Conversion } \\
\text { factor } \\
\text { (referred to } \\
\text { conventional } \\
\text { fuel) }\end{array}$ & Dimensionless & 0.85 & 0.97 & 0.99 & 1.00 & 0.76 & 1.00 & 1.00 \\
\hline
\end{tabular}

Remark: Data referred to the averaged figure of actual test driving on by $\mathrm{P}$.

Calculation scheme of power production process is illustrated in Fig. 4. It is initially starting with the evaluation of power supply need. Peak power requirement is evaluated from the electricity demand obtained by the product of final electricity consumption and the current averaged load factor of 0.75 . For 
the supply side, power production as well as import/export target options have been allowed for fulfilling the peak power requirement. In this study, the entire power supply option including the power import target is designated by the national plan. Planned installed and retired capacity of the power plant in each process have been treated as the exogenous input parameters. Under this process, the required feedstock is calculated for the demand of primary resources. The utilized assumption of power plant characteristics has been illustrated in Table 2.

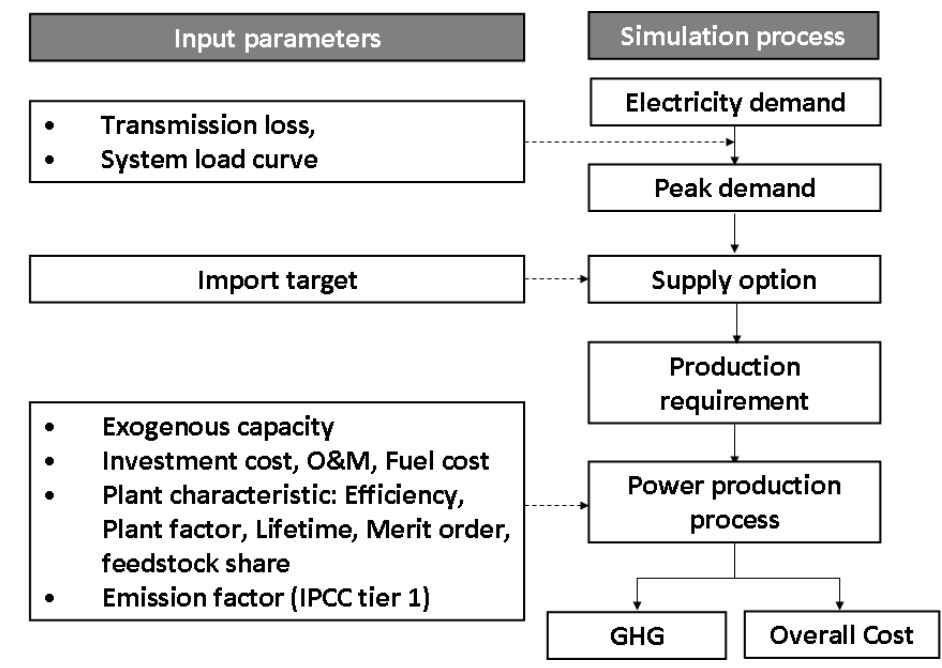

Fig. 4. Calculation scheme for power production process.

Table 2. Characteristic of power production technology $[9,10]$.

\begin{tabular}{lcccc}
\hline \multirow{2}{*}{ Technology } & \multicolumn{4}{c}{ Technical Assumption } \\
\cline { 2 - 5 } & Size & Life time & Efficiency & $\begin{array}{c}\text { Capacity } \\
\text { Factor }\end{array}$ \\
\cline { 2 - 5 } & $\mathbf{M W}$ & $\mathbf{y r}$ & $\mathbf{\%}$ & $\mathbf{\%}$ \\
\hline Hydro power & 1000 & 50 & 38 & 45 \\
Thermal: Oil-fired & 700 & 30 & 35 & 80 \\
Thermal: Coal-fired with FGD & 700 & 30 & 35 & 90 \\
Combined cycle & 700 & 20 & 45 & 90 \\
Gas turbine & 230 & 20 & 35 & 90 \\
Nuclear & 1000 & 30 & 35 & 90 \\
Biomass & 80 & 30 & 35 & 50 \\
Biogas & 10 & 30 & 30 & 50 \\
Waste & 10 & 30 & 30 & 50 \\
Wind & 10 & 20 & 15 & 20 \\
PV & 5 & 20 & 15 & 15 \\
\hline
\end{tabular}

The GHG emission is directly calculated based on the methodology and emission factors recommended by IPCC, which are mostly identical with the figures published by Thailand Greenhouse Gases Organization (TGO). Since there is a gap between the existing database of TGO and the requirement of the utilized model, the default emission factor of tier 1 of IPCC is chosen for the overall calculation. The coverage of GHG emission calculation is restricted to the direct combustion of final energy consumption and transformation process of power production. It does not cover the upstream process of feedstock preparation and waste management. 


\section{Scenarios}

\subsection{The reference scenario}

The reference scenario represents the target future prospect under the pathway of current government policy. Economic ambitious and energy security is considerably the first priority among other key drivers. Ambitious targets of national plan are presumed on target achievement. The key assumptions of the reference scenario are as follows

Long-term country economic growth is treated as the major key factor to shape overall energy requirement. It is presumed at the rate of approximately 4 percent annually in coherent with the reference case for the national power development plan (PDP2010) [11]. There is no significant change in major economic structure along the calculation period (2009-2030). For sensitivity testing, the final energy consumptions corresponding to the variation of GDP growth rate for the high and low cases is illustrated in Fig. 5. It can be seen that the optimistic of economic growth in the high case is resulting in the increasing of final energy consumption by approximately 4.1 percent. In contrast, the pessimistic prospect in the low case is resulting in the decreasing of final energy consumption by approximately 4.2 percent in 2030 , compared to the REF case.

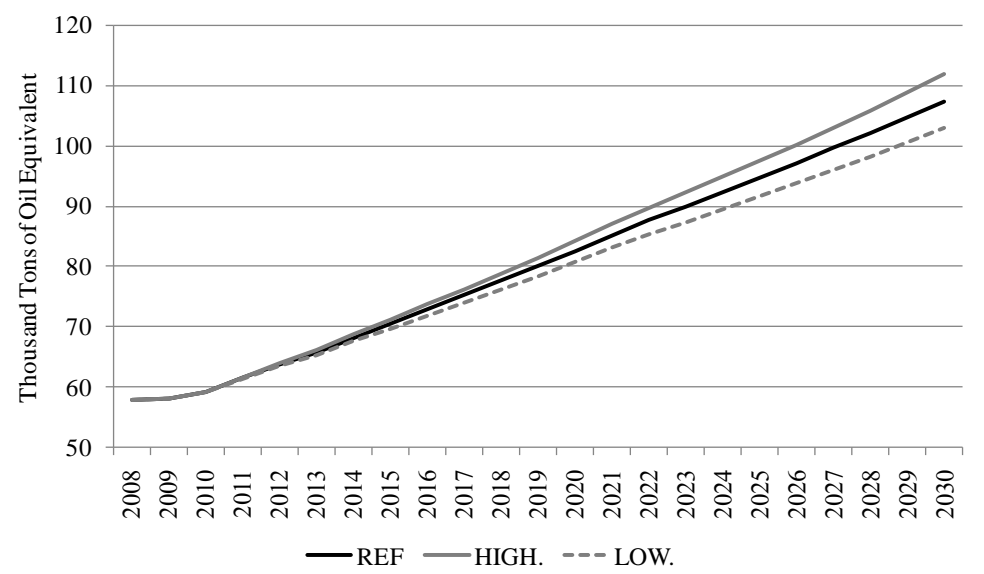

Fig. 5. Sensitivity testing of energy demand and economic growth.

Population is increasing at slower rate year by year from a number of 66.4 million people in 2009 to 70.5 million people within 2030. This figure refers to the previous publication of National Economic and Social Development Board. [12]. Sectoral energy intensities are continuously improved at the same rate of historical development. The switching of road to rail transportation can be implemented according the master plan of national transportation development [13] as illustrated in Fig. 6. In this scenario, there is an optimistic prospect on renewable energy market. Utilizations of renewable energy are driven to achieve the target of Alternative Energy Development Plan (AEDP) [14]. Alternative fuels can penetrate to approximately 20 percent of final energy demand in 2030 as illustrated in Fig. 7.

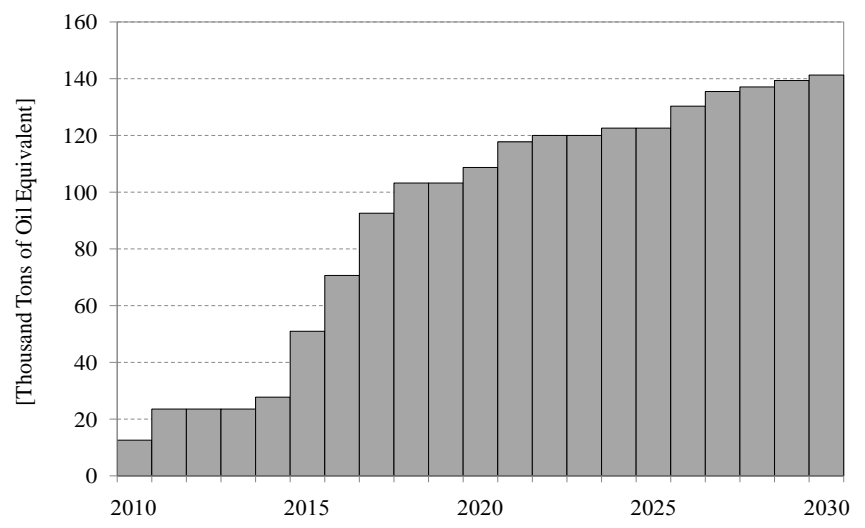

Fig. 6. Estimated electricity consumption of railway massive transport in the Greater Bangkok according to the national transportation master plan. 


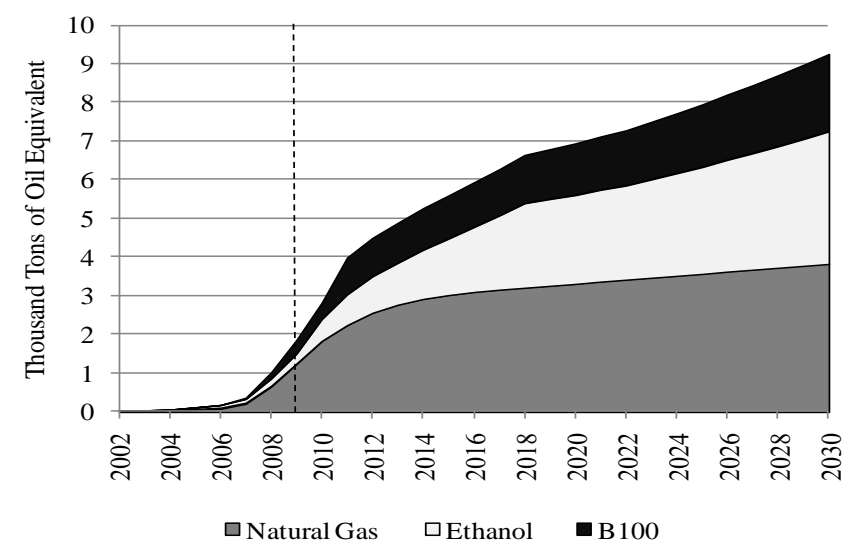

Fig. 7. Target of alternative energy consumption in transportation sector according to the AEDP.

Fuel options for power supply rely on the national power development plan. Coal, nuclear, renewable energy and power purchasing are all the options to diversify the great dependency on natural gas, which is accounted for 70 percent as illustrated in Fig. 8.

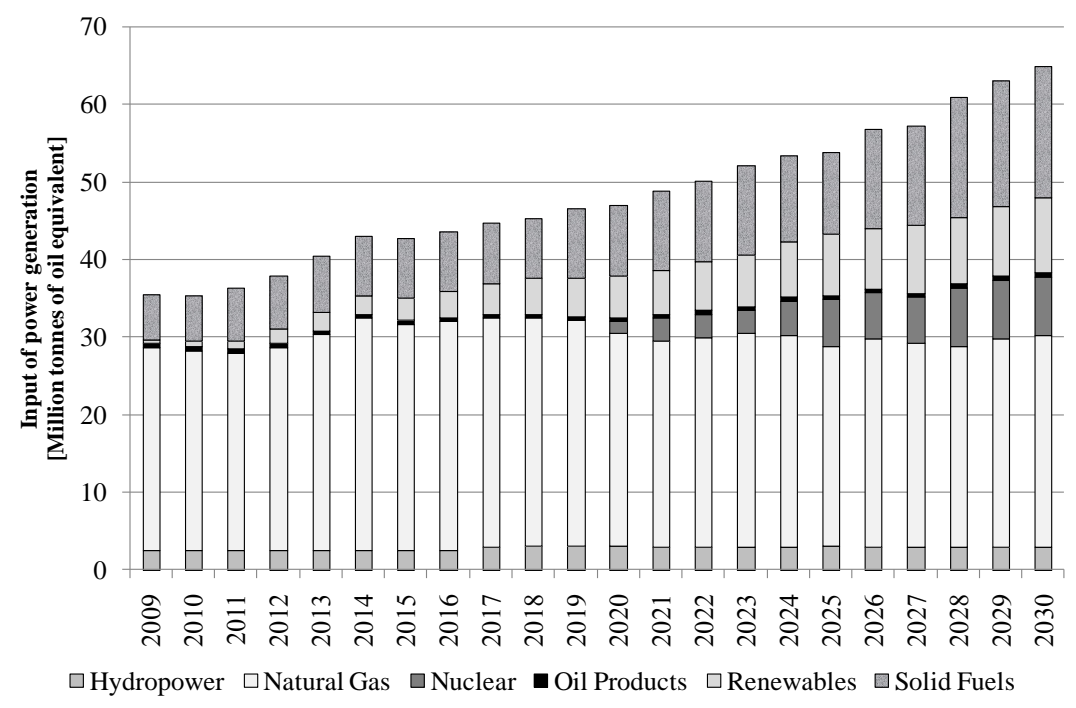

Fig. 8. Fuel mix for power generation according to the PDP2010.

\subsection{The case without plan}

The case without plan presents the pessimistic prospect on ambitious target of national plan including the renewable energy development. It is assumed that all of national targets are not able to completely start implementing with any reasons. It must be noted that this situation is rarely occurred in reality. The case without plan aims to reveal the impact of the existing plan, in particular the prospect of greenhouse gas mitigation potential. The key assumptions of the case without plan are as follows

The development of massive rail transportation in the Greater Bangkok (12 lines with total distance of $509 \mathrm{~km}$ ) and intercity railway (4 major lines with total distance of $3000 \mathrm{~km}$ ) under the master plan are unable to implement. In this case, road transportation is kept growing and continuously take the majority of the country transportation. The markets of alternative fuel, e.g. bio-fuel and natural gas for vehicle, are unable to penetrate to the road transportation market. There is no additional utilization of alternative fuel compared to the level of base year figure. In this case, the consumption of petroleum product will keep growing without alternative fuel substitution. 
The commissioning of 5 nuclear power plants, with installed capacity of 5,000 MW, are unable to accomplish. In this case, additional combination of the combined cycle and coal-fired power generation is required to fill up the gap and maintain reserve margin of the power system at the level of 15 percent.

\subsection{The case with additional plan}

The case with additional plan represents an alternative scenario of additional non-existing policies and measures on greenhouse gas mitigation. In this case, the selected measures of energy efficiency scheme with more concern on power decarbonisation is comparatively simulated. The key assumptions of the case with additional plan are as follows

The mandatory approach of fuel economy and emission standard are seriously taken into the action for road transportation. It is assumed that energy efficiency will be improved by 40 percent within 2030, compared to the current account. The current figures are derived by the averaging of sampling survey in the greater Bangkok area [15]. The level of energy efficiency improvement is relied on the target of Corporate Average Fuel Economy standard (CAFE) [16] as illustrated in Fig. 9.

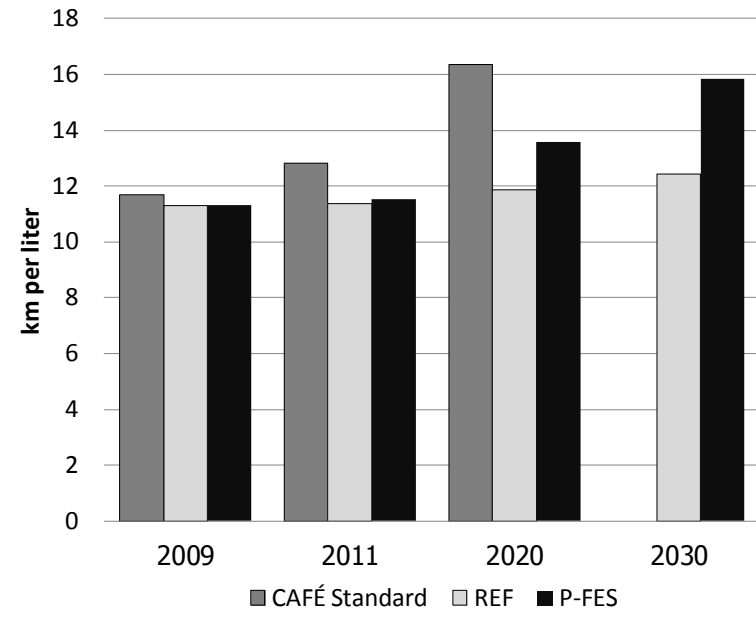

(a) Gasoline engine

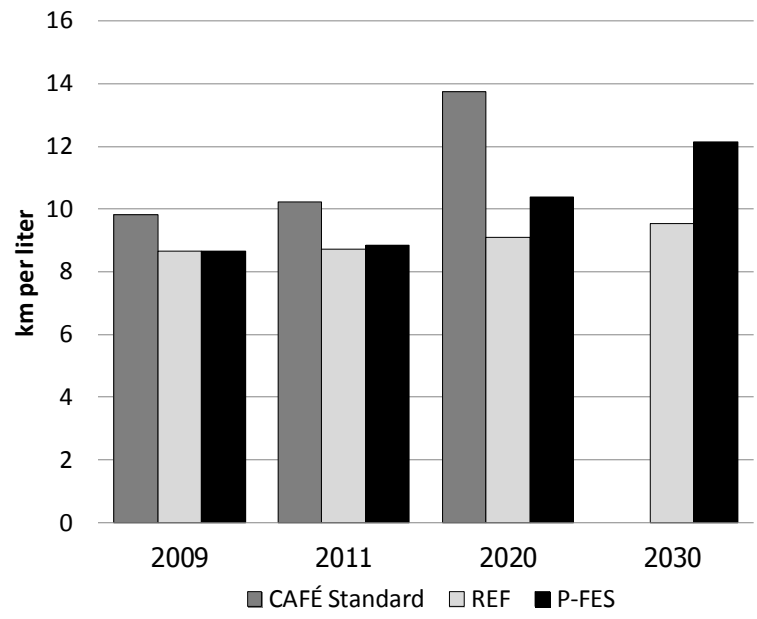

(b) Diesel engine

Fig. 9. Assumption of fuel economy in road transport (Remark: P-FES referred to the case with additional plan of fuel economy standard).

The additional scheme of energy efficiency improvement in industry sector is applied in particular the incentives to promote best available efficient technology in the industrial process. In this case, the highenergy intensive industrial sectors of basic metal production, paper and chemical industries has been selected. It is assumed that the efficiency will be improved by 20 percent by 5 year ahead in according to the current best available technology worldwide [14] as illustrated in Fig. 10. Furthermore, fuel mix policy for the Power Development Plan (PDP) is revised to concern more on clean energy. In this case, the planning of coal-fired power plant is replaced by the increasing of nuclear power from 10 percent to 15 percent of fuel mix to maintain the based load power production at the same level of the PDP. 


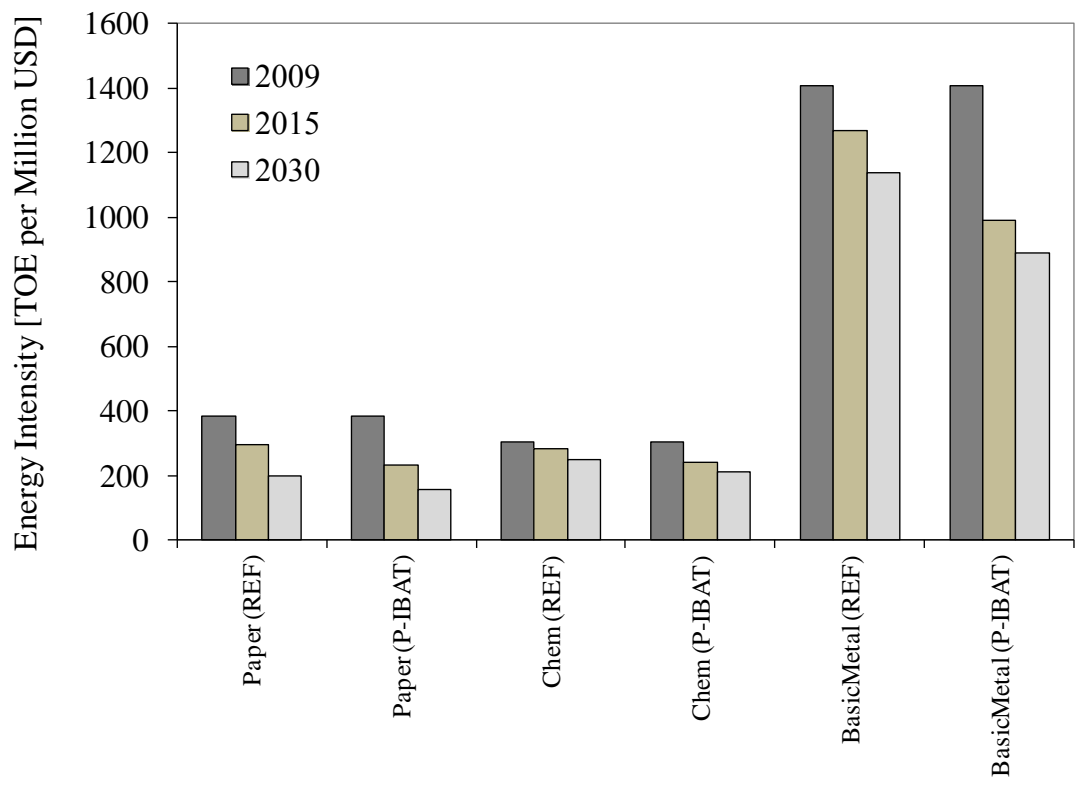

Fig. 10. Assumption of energy intensity in the selected industrial sub-sectors (Remark: P-IBAT referred to the case with additional plan of utilizing best available technology).

\section{Results and discussions}

The outlook of energy-related GHG emission capita for Thailand is illustrated in Fig. 11. It is obviously seen the continuous increasing of GHG emission year by year in all cases. In the reference scenario, the GHG emission will increase from currently 3 tonnes per capita to 4.6 tonnes per capita by 20 year ahead. The case without plan will cause much higher GHG emission by 11.1 percent, while the case with additional plan will be able to reduce the GHG emission by 13.0 percent compared to the reference case. The results clearly show the importance of the existing and selected additional measures on the GHG mitigation. However, the existing plan does not contribute to the energy efficiency improvement as illustrated in Fig. 12. There is no significant deviation of energy intensity between the reference and the case without plan. This leads to the recommendation that Thailand energy policy should point out seriously on the energy efficiency scheme. On the other hand, the case of additional policy can improve significantly the energy efficiency by 9.2 percent in 2030. It must be noted that this figure rely on the energy efficiency improvement on only two measures in two major sectors of transportation and industry. There is still a gap to achieve full potential of GHG mitigation, particularly by the energy efficiency scheme.

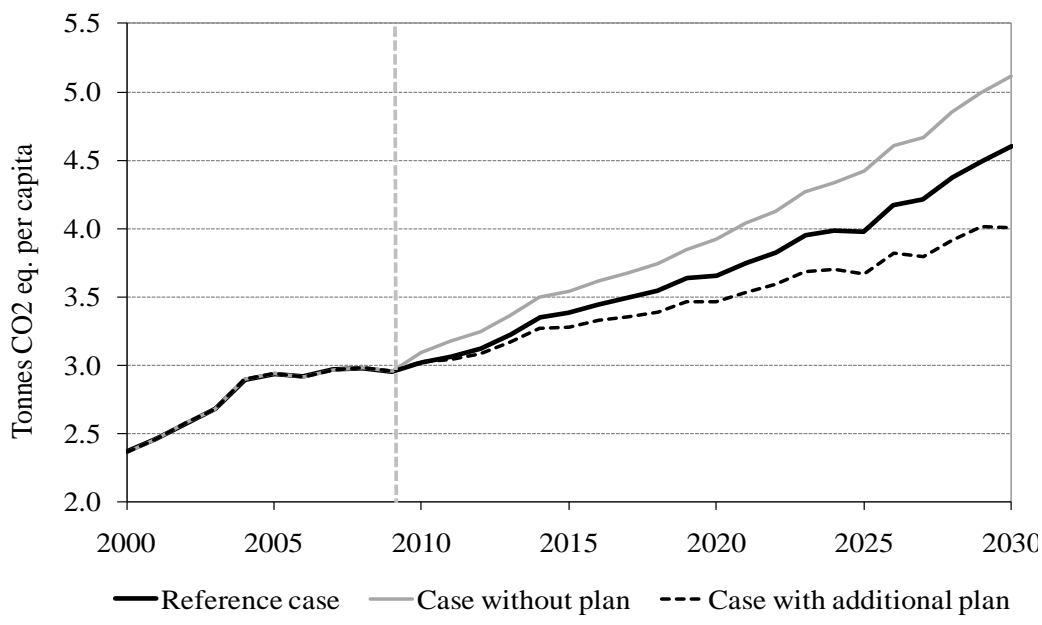

Fig. 11. GHG emission per capita. 


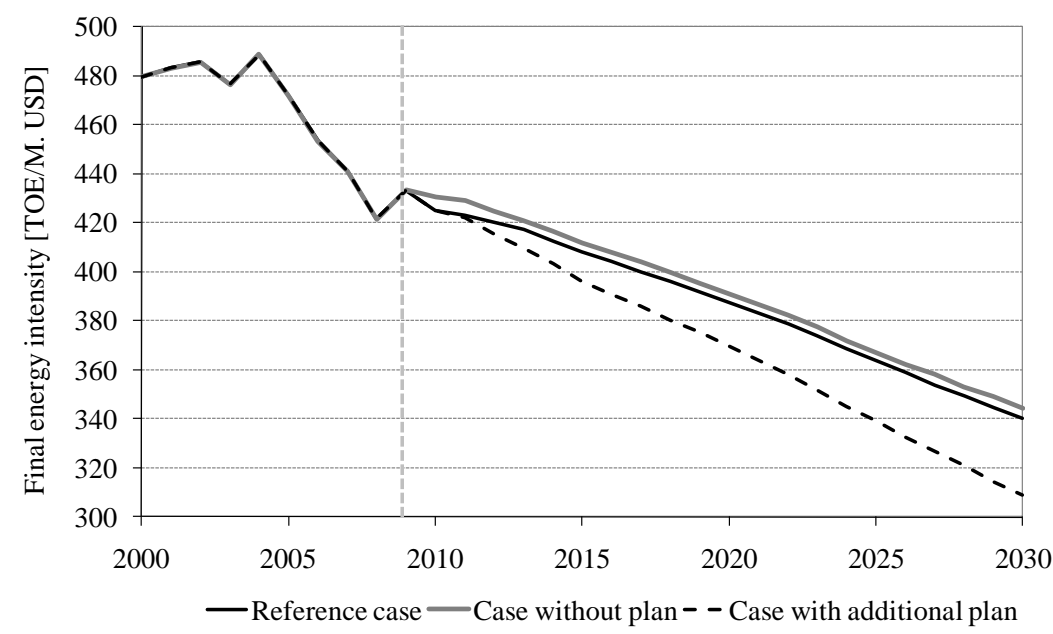

Fig. 12. Energy intensity.

The relative GHG mitigation potential by individual measures in each case is illustrated in Fig. 13. Among the existing plan, bio-fuel and nuclear make a crucial impact on the GHG mitigation. They are accounted for approximately $70-80$ percent contribution to the GHG mitigation of the existing plan. Thus, uncertainty of nuclear power commissioning and resource availability of bio-fuel production will be the key factors for the achievement of GHG mitigation target of Thailand. For the case of additional plan, the action of fuel economy standard enforcement will take a major rule for the GHG mitigation. It must be noted that this study focus on the impact on the GHG mitigation regardless the factor of cost and investment required for policy maker decision. In addition, it also does not take other indirect impact, which might be considered for the policy decision, e.g. impact of land-use change and food pricing for biofuel, nuclear waste and decommission cost and etc.

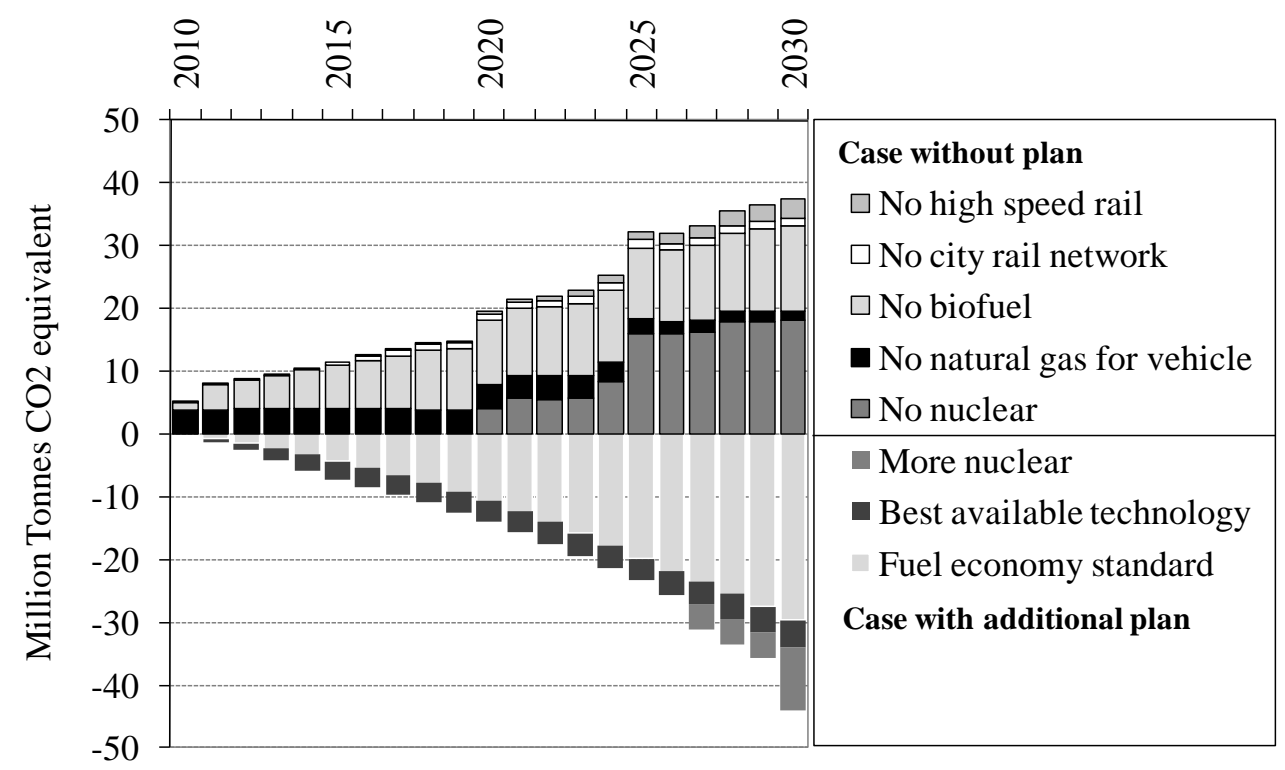

Fig. 13. Relative GHG mitigation potential compared to the reference case.

\section{Conclusions}

The results indicate the importance of the existing and additional plan to cope with the challenges of GHG mitigation requirement and energy policy in Thailand. The results show that the current official target and energy policy in Thailand are emphasized on the energy supply security basis with the ambitious target of 
alternative clean energy. In the case with additional plan, the result also shows significantly the improvement of energy intensity, while the case without plan does not make a difference with the reference case. However, the energy efficiency scheme has been proved to be the major mechanism for GHG mitigation. In this study, regulation of fuel economy standard and bio-fuel option in transportation as well as nuclear power generation are considered as the most effective measures in term of GHG mitigation among the selected potential policies. It must be noted that the conclusions are derived by the potential of GHG reduction without taking other indirect impact into the account, e.g. impact of land-use change and food pricing for biofuel, nuclear waste and decommission cost and etc.

\section{Acknowledgement}

The content presented in this paper is part of the National Research University Project of CHE and Ratchadaphiseksomphot Endowment Fund (EN1182A).

\section{References}

[1] J. Santisirisomboon, "Least cost electricity generation options based on environmental impact abatement," Energy Policy, vol. 6, pp. 533-541, 2003.

[2] S. Tanatvanit, B. Limmeechokchai, and S. Chungpaibulpatana, "Sustainable energy development strategies: implications of energy demand management and renewable energy in Thailand," Renewable and Sustainable Energy Review, vol. 7, pp. 376-395, 2003.

[3] W. Wangjiraniran and B. Eua-arporn, "The outlook of energy-related GHG emission in Thailand," presented at Fostering Economic Growth through Low Carbon Initiatives in Thailand, Bangkok, Thailand, Feb. 25-26, 2010.

[4] W. Wangjiraniran and B. Eua-arporn, "A study on fuel options for power generation in Thailand," Engineering Journal, vol. 14, No. 3, pp. 35-44, 2010.

[5] Stockholm Environment Institute (SEI). [Online]. Available: http://www.energycommuity.org/

[6] Department of Alternative Energy Development and Efficiency (DEDE), Ministry of Energy. [Online]. Available: http://www.dede.go.th/

[7] World Energy Model - Methodology and assumption, International Energy Agency (IEA), 2010. [Online]. Available: http://www.iea.org/weo/model.asp

[8] Energy Technology Perspectives - Scenarios and Strategies to 2050, International Energy Agency (IEA), 2010. [Online]. Available: http://www.iea.org/

[9] Electricity Generation Authority of Thailand (EGAT), 2010.

[10] Renewable Electricity in the APEC Region: Internalising Externalities in the Cost of Power Generation Asia Pacific Energy Research Centre (APERC), 2005. [Online]. Available: http://www.ieej.or.jp/aperc

[11] Power Development Plan, Electricity Generation Authority of Thailand (EGAT), 2010. [Online]. Available: http://www.egat.co.th/

[12] Population Projection for Thailand (2000-2030), Office of the National Economic and Social Development Board (NESDB), 2007. [Online]. Available: http://www.nesdb.go.th/

[13] Master Plan of Railway Transportation Network, Office of Transport and Traffic Policy and Planning (OTP), 2010.

[14] Alternative Energy Development Plan 2009-2022 (AEDP), Department of Alternative Energy Development and Efficiency (DEDE), 2009. [Online]. Available: http://www.dede.go.th/

[15] Study on Transportation and Logistic Cost in Thailand, Office of Transport and Traffic Policy and Planning, Ministry of Transport (MOT), 2010.

[16] National Highway Traffic Safety Administration (NHTSA). [Online]. Available: http://www.nhtsa.gov/ 
